\title{
Is the groundwater reservoir linear? A mathematical analysis of two limiting cases
}

\section{G. H. de Rooij}

Helmholtz Institute for Environmental Research - UFZ, Halle (Saale), Germany

Received: 2 December 2013 - Accepted: 10 December 2013 - Published: 6 January 2014

Correspondence to: G. H. de Rooij (gerrit.derooij@ufz.de)

Published by Copernicus Publications on behalf of the European Geosciences Union.

Is the groundwater reservoir linear? A

mathematical

analysis

G. H. de Rooij

Title Page

Abstract Introduction

Conclusions References

Tables Figures

14

$\triangleleft$

Back

Full Screen / Esc

Printer-friendly Version

Interactive Discussion 


\section{Abstract}

Storage-discharge relationships of the groundwater reservoirs of several catchments in a temperate-humid climate were reported in the literature to be seemingly non-linear. Once recharge was adequately accounted for during model calibration they turned out 5 to be linear. The question was posed if this linearity was a fundamental property of groundwater reservoirs in general. A mathematical analysis based on analytical solutions for several cases involving parallel flow in horizontal aquifers shows that this is not the case when the surface water level is close to the aquifer bottom. When the aquifer is of constant thickness, linear-reservoir behaviour arises when the forcings remain 10 constant for a sufficiently long time. This can range from a few weeks for aquifers with a dense drainage network of streams or ditches to years or centuries for large aquifers drained by rivers many kilometers apart. The characteristic time of the groundwater reservoir depends on whether or not the aquifer is leaky and recharge is non-zero. It is concluded that groundwater reservoirs can only be linear if their thickness can be assumed independent of the hydraulic head, and if they have a dense drainage network. Even then, they behave non-linearly up to several weeks after a change in recharge. Models that conceptualize the catchment as a configuration of coupled reservoirs will normally assign the groundwater discharge surplus generated because of the initially non-linear behaviour of the groundwater to their fast-responding reservoirs, thereby exaggerating the importance of fast-responding flow routes in a catchment.

\section{Introduction}

Catchment hydrologists have long concerned themselves with the relationship between stream discharge and the amount of water present in the subsurface domain of the catchment. The prolonged attention devoted to this relationship has resulted in a variety of modelling concepts (e.g. Birtles, 1978; Brutsaert, 2005, 486-493). For many purposes and at many locations, full-scale physical modelling of the hydrology of
HESSD

11, 83-108, 2014

Is the groundwater reservoir linear? A

mathematical analysis

G. H. de Rooij

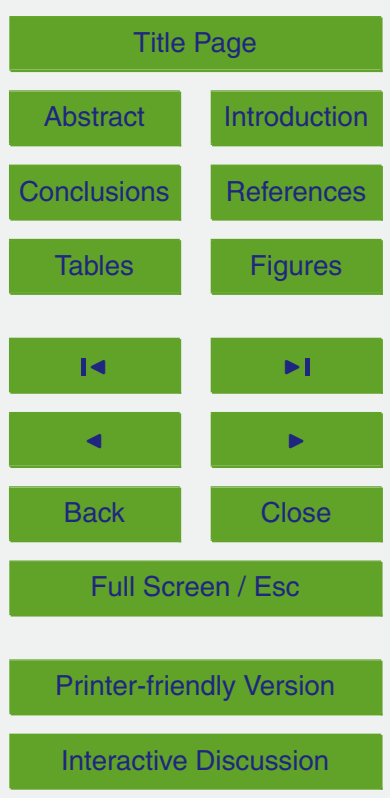


a catchment remains to this day overly ambitious, if not outright impossible, owing to the complicated hydrogeology, topography, and pedology, different land cover, etc., of even small catchments. Relatively simple storage-discharge relationships therefore abound (Tallaksen, 1995), with the linear reservoir being the most popular, owing to its conve5 nience and often adequate agreement with observations (Zecharias and Brutsaert, 1988; Vogel and Kroll, 1992). Nevertheless, the suitability of the various storagedischarge relationships remains the subject of continued debate (e.g. Wittenberg and Sivapalan, 1999; Wittenberg, 2003). Their simplicity notwithstanding, many storagedischarge models distinguish between various subsurface storage reservoirs within a catchment, each with its characteristic time representative of the time required for the water in a particular reservoir to be transferred to the stream, or to another reservoir in case the model permits sequences of reservoirs (e.g. Moore, 1997). One of these reservoirs is the groundwater, typically considered to be responsible for low but prolonged discharge (baseflow) (Werner and Sundquist, 1951; Moore, 1997; Hornberger 15 et al., 1998, p. 164).

Fenicia et al. (2006) posed the question "Are groundwater reservoirs linear?" The question arose from their observation that an improved calibration procedure that did not a priori assume a particular form of the slow hydrograph component (attributed to exfiltration of groundwater into the stream) indicated that in all but one of their test catchments, the groundwater reservoir trended toward linear behaviour in subsequent iterations in the calibration procedure. The work suggested that omitting the effect of groundwater recharge could distort the apparent storage-discharge relationship, and thus hide the inherent linearity of the groundwater reservoir.

Fenicia et al.'s (2006) catchments were in gently sloping areas. Furthermore, numer25 ical solutions for various slope types (Troch et al., 2003; Hilberts et al., 2004) showed no evidence of linearity. This paper therefore focuses on horizontal aquifers to unveil if there is mathematical support for the hypothesized linearity. The aquifers are uniform with stream tubes that are parallel in the horizontal plane. Two limiting cases, with the surface water level either at the aquifer bottom or near the top, are considered.

\section{HESSD}

$11,83-108,2014$

Is the groundwater reservoir linear? A

mathematical analysis

G. H. de Rooij

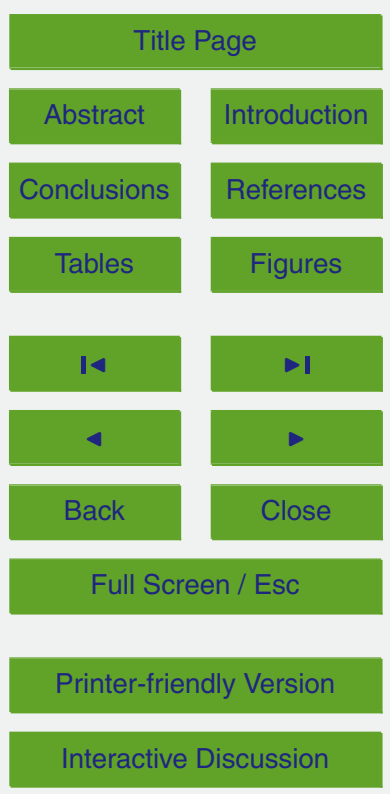


Both cases are valid for horizontal or mildly sloping aquifers with parallel flow. Other configurations (steeper slopes, converging or diverging flow) can lead to discharge behaviour outside the range enveloped by the cases presented here. Chapman (1999), for instance, attributes values larger than 2 of the exponent in a power law storage5 discharge relationship to flow convergence in the groundwater system (a linear reservoir's exponent equals 1 ).

\section{Aquifer-scale analysis}

In Darcy's Law for the flux density at the local scale, the derivative of the hydraulic potential $H[\mathrm{~L}]$ appears. The local equation of mass continuity in turn requires the 10 derivative of the flux density. This leads to the second-order derivative of $H$ in the flow equation that arises when the continuity equation and Darcy's Law are combined. This double differentiation of the potential is the fundamental reason why flows driven by gradients in a suitably defined potential (such as concentration gradients driving diffusion and voltage gradients driving electrical currents) are governed by second-order 15 partial differential equations. The need for the double differentiation is arises from the fundamental continuity of the potential in space. If we are interested in scales much larger than the Darcian scales, we may not be interested in or able to acquire the fields of the hydraulic potential and the related geohydrological parameters in such detail that we can rely on Darcian scale models. If we work with larger-scale observations,

the continuity of whatever property we choose to describe the state of the water in a hydrological unit (e.g. the unsaturated soil of an agricultural field, an aquifer, etc.) at the super-Darcian scale is by no means guaranteed. Furthermore, at that scale the interest will largely lie in the exchange of water between different hydrological units. This is illustrated by the papers discussed in the Introduction. They were mostly concerned with the transfer of water from an aquifer to the stream, from a soil cover to an aquifer, etc. The mass balance of any hydrological unit will contain terms describing the flux across its boundaries, which it shares with other hydrological units. To define

\section{HESSD}

$11,83-108,2014$

Is the groundwater reservoir linear? A

mathematical analysis

G. H. de Rooij

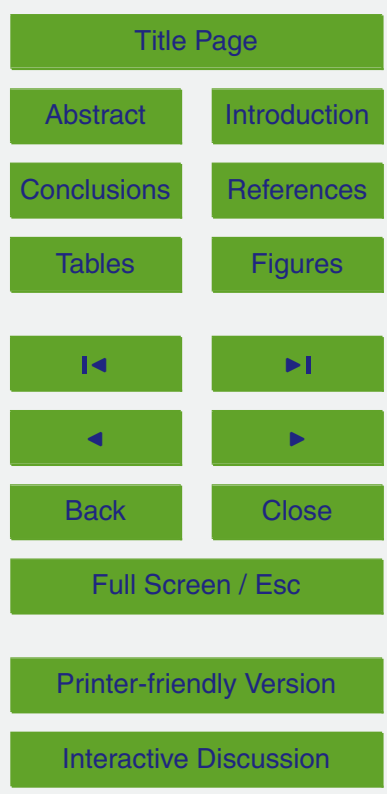


these terms it will usually not be necessary to find the gradient of these fluxes within the hydrological unit. This eliminates the first of the two differentiations that are fundamental to the Darcian flow equations for subsurface flows. It is therefore unlikely that second-order partial differential equations will be of use at the super-Darcian scale.

5 This can be illustrated for the simplified geometry of an aquifer in the shape of an infinitely long strip between a water divide (no-flow boundary) on one hand and a straight canal or stream on the other (Fig. 1). The mass balance for this system is easy to construct (de Rooij, 2013):

$$
\mu L \frac{\mathrm{d}\left(\bar{H}(t)-H_{A}\right)}{\mathrm{d} t}=L(b+R(t))+a \int_{0}^{L} H(x, t) \mathrm{d} x-Q(L, t)
$$

10 where $x[\mathrm{~L}]$ is the horizontal coordinate in the principal flow direction perpendicular to the stream, $Q\left[\mathrm{~L}^{2} \mathrm{~T}^{-1}\right]$ is the flux across the groundwater-surface water interface for a unit length of the bank (negative for water leaving the aquifer), $L(L)$ is he distance between the water divide and the stream bank, $t[\mathrm{~T}]$ is time, $H_{A}[\mathrm{~L}]$ is the constant hydraulic potential in the surface water (at $x=L$ ), $\mu$ is the storativity (confined aquifer) or specific yield (phreatic aquifer), $a\left[\mathrm{~L}^{-1}\right]$ and $b\left[\mathrm{LT}^{-1}\right]$ govern the potential-dependent recharge or extraction, while $R\left[\mathrm{LT}^{-1}\right]$ is the potential-independent recharge or extraction. The latter is assumed uniform in space, but generalization to non-uniform $R$ across $L$ is trivial. If $a$ and $b$ are used to describe the exchange of water between the aquifer of interest and a second aquifer with hydraulic potential $H_{2}$ [L], the flow through the aquitard that separates the aquifers equals $a\left(H-H_{2}\right)$ (since $a<0$, flow into the primary aquifer is positive), so that $a$ is the opposite of the reciprocal of the aquitard resistance, and $b=-a H_{2}$. In that case, $b$ must necessarily be zero if $a$ equals zero. The hydraulic potential is set to zero at the aquifer bottom without loss of generality. An overbar indicates the spatial average of a variable. The left-hand side term of the mass balance represents the storage change. The inclusion of the constant $H_{A}$ in the temporal derivative is mathematically not required but will prove useful later in the analysis.
HESSD

$11,83-108,2014$

Is the groundwater reservoir linear? A mathematical analysis

G. H. de Rooij

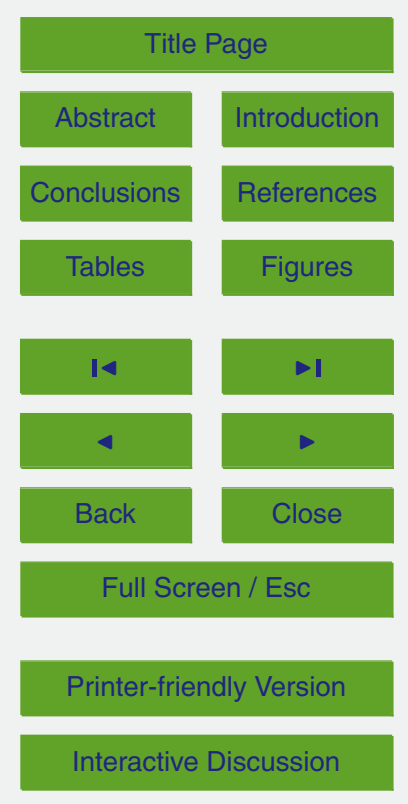


The aquifer-scale equivalent of the equation of motion is an equation that describes the exchange $Q$ between the aquifer and the stream. In accordance with de Rooij (2013) we simply assume $Q$ to be a function of the difference between the average hydraulic potential in the aquifer and the stream:

${ }_{5} Q(t)=K_{\text {up }}(t)\left(\bar{H}(t)-H_{A}\right)$.

The proportionality factor $K_{\text {up }}\left[\mathrm{LT}^{-1}\right]$ was termed the aquifer-scale hydraulic conductivity by de Rooij (2013) to reflect the analogy between Eq. (2) and Darcy's Law. Unlike the Darcian hydraulic conductivity, it is non-unique, since many different shapes of the phreatic surface can give the same average hydraulic potential but generate very dif10 ferent values of $Q$ and vice versa. It is also non-constant. Importantly, it does have the Darcian property of being independent of the magnitude of $\bar{H}(t)-H_{A}$. With this expression for $Q$ and the mass balance of Eq. (1) the aquifer-scale flow equation follows (de Rooij, 2013):

$\mu L \frac{\mathrm{d}\left(\bar{H}(t)-H_{A}\right)}{\mathrm{d} t}=L(b+R(t))+a L \bar{H}(t)-K_{\text {up }}(t)\left(\bar{H}(t)-H_{A}\right)$.

15 As anticipated above, this is not a second-order partial differential equation in $H$ but instead a first-order ordinary differential equation in $\bar{H}-H_{A}$. Its coefficients are nonconstant. It is important to note that no assumptions regarding the thickness of the aquifer are necessary to arrive at Eq. (3).

Fenicia et al. (2006) found that aquifers in different geological strata in a humid-

temperate climate behaved like linear reservoirs. This is consistent with Eq. (3) when its coefficients are constant. Linear-reservoir behaviour thus requires that $R$ and $K_{\text {up }}$ are both constant for a sufficiently long period of time. At this time, expressions for $K_{\text {up }}$ that permit an examination of the conditions that lead to a constant value are only available for uniform aquifers of constant thickness (de Rooij, 2013). This is one of the

\section{HESSD}

$11,83-108,2014$

Is the groundwater reservoir linear? A

mathematical

analysis

G. H. de Rooij

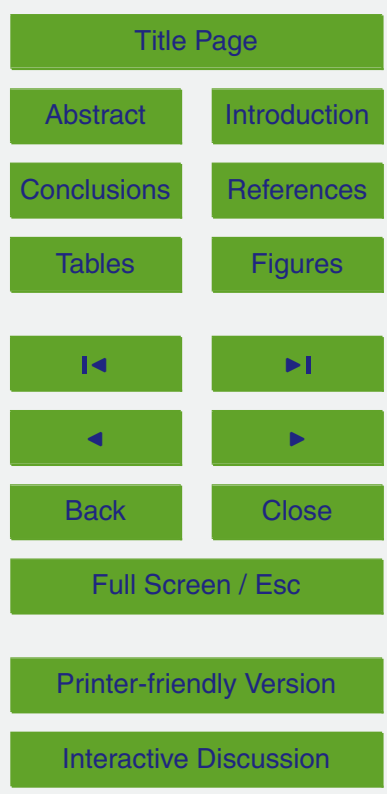




\section{Governing equations at the Darcian scale}

A more conventional approach than the aquifer-scale analysis above to find answers to Fenicia et al.'s (2006) question is to analyse groundwater flows within the Darcian framework. For flows in horizontal, uniform aquifers, two limiting cases can be distin5 guished (see also Chapman, 1999): the case of phreatic groundwater flow where the surface water level is at the same height as the aquifer bottom, and the case where the surface water level is high enough to allow the flow lines close to the outlet (the interface between the aquifer and the surface water) to remain parallel to the aquifer bottom. In the first case, the thickness of the saturated zone drops to zero at the groundwatersurface water interface. In the second case, the aquifer thickness is essentially constant over its entire width between the water divide and the surface water. Whether the aquifer is phreatic or confined is immaterial for the mathematical analysis in that case, although it has a large effect on the storativity/specific yield of the aquifer (de Rooij, 2012).

By invoking the Dupuit assumptions (zero vertical gradient in the hydraulic potential, zero vertical flow velocity, no vertical variations in the horizontal flow velocity) and simplifying the aquifer to a semi-infinite strip between a stream and a water divide running parallel to one another, the problem can be reduced to one dimension and described by the Boussinesq equation:

20

$\mu \frac{\partial H}{\partial t}=K\left[\frac{\partial}{\partial x}\left(H \frac{\partial H}{\partial x}\right)\right]+a H+b+R$

where $K\left[\mathrm{LT}^{-1}\right]$ is the hydraulic conductivity. The first case (surface water level at the aquifer bottom) was solved by Boussinesq (1904, as cited by Brutsaert and Nieber, 1977) for early times by replacing the bounded aquifer by a semi-infinite one that was initially fully saturated, and for prolonged time for a specific initial phreatic level described by an incomplete beta-function between the water divide and the surface water. In both cases, $a=b=R=0$ to keep the problem analytically tractable. Brutsaert
HESSD

11, 83-108, 2014

Is the groundwater reservoir linear? A

mathematical analysis

G. H. de Rooij

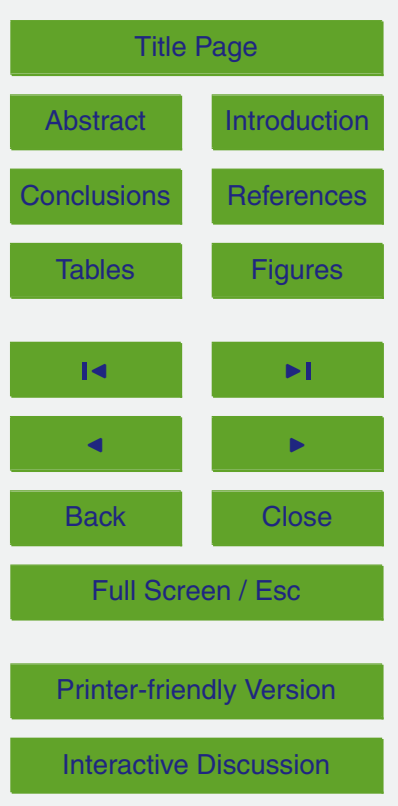


and Nieber (1977) discussed both solutions in detail. They labelled the flow system a Dupuit-Boussinesq aquifer (Fig. 2).

The second case is much simpler owing to its constant thickness $D$ [L], which allows Boussinesq's equation to be linearized by setting $H(x)=D$ :

$5 \frac{\partial H}{\partial t}=\frac{K D}{\mu} \frac{\partial^{2} H}{\partial x^{2}}+\frac{a H}{\mu}+\frac{b+R}{\mu}$.

De Rooij (2012) was therefore able to present an analytical solution for a much broader class of problems: the surface water is kept at a constant potential, which may differ from the uniform initial potential within the aquifer. Uniform recharge or extraction is possible $(R \neq 0)$, and the solution allows one step change between two constant values

10 of $R$ at an arbitrary time. In addition, the aquifer may be leaky $(a, b \neq 0)$. This allows a quantitative analysis of the effect of recharge on the flow into or from the stream, effects that Fenicia et al. (2006) speculated about. The aquifer can be an infinitely long strip but may also be circular (with $x$ representing the radial coordinate), in which case it represents a circular island in a lake or a circular field surrounded by a canal. Here, 15 only the strip aquifer will be examined (Fig. 3).

\section{Water flow between the aquifer and the stream}

According to Brutsaert and Nieber (1977), the outflow from the aquifer bordering a stream with the water level at the aquifer bottom was proportional to $t^{-1 / 2}$ shortly after the start of the outflow at $t=0$. Thus we have:

while at the same time mass conservation requires

$Q=-L \frac{\mathrm{d} S_{p}}{\mathrm{~d} t}$

Is the groundwater reservoir linear? A

mathematical

analysis

G. H. de Rooij

Title Page

Abstract

Introduction

Conclusions

Tables

References

Figures

14

$>1$

4

Back

Close

Full Screen / Esc

Printer-friendly Version

Interactive Discussion 
where $S_{p}[\mathrm{~L}]$ is the storage in the aquifer between the surface water and the water divide expressed as an equivalent water layer, and $c_{1}\left[\mathrm{~L}^{2} \mathrm{~T}^{-1 / 2}\right]$ is an aquifer-specific constant ( $>0$ ). Combining Eqs. (6) and (7), solving by separation of variables, and some manipulation leads to:

${ }_{5} Q(t)=\frac{2 c_{1}^{2}}{L\left(S_{p}(0)-S_{p}(t)\right)}$.

The discharge is proportional to the reciprocal of the storage deficit. Alternatively, discharge is often assumed to be related to storage by a power law relationship:

$Q(t)=c_{2}\left(S_{p}(t)\right)^{j}$

The exponent $j$ is arbitrary, the constant $c_{2}\left[\mathrm{~L}^{2-n} \mathrm{~T}^{-1}\right]$ is larger than zero. Chapman 10 (1999) states that conditions similar to those imposed by Brutsaert and Nieber (1977), notably a very shallow surface water level, lead to $j=2$, i.e. clearly non-linear behaviour. Equation (9) can be combined with Eq. (7). After solving by separation of variables, an expression for $S_{p}^{n}$ can be developed from the solution and multiplied by $c_{2}$. For $j \neq 1$ the result is:

${ }_{15} Q(t)=Q(0)\left[c_{2}(1-j)\left(S_{p}(0)\right)^{j-1} t+1\right]^{\frac{j}{1-j}}$

(a slightly more specific version than Brutsaert and Nieber's, 1977). For $j=1$, the equation for the linear reservoir is obtained:

$Q(t)=Q(0) \mathrm{e}^{c_{2} t}$

The long-term solution as given by Brutsaert and Nieber (1977) to the flow problem in the Dupuit-Boussinesq aquifer with the exit water level at the aquifer bottom is of

Is the groundwater reservoir linear? A

mathematical

analysis

G. H. de Rooij

Title Page

Abstract

Introduction

Conclusions

Tables

References

Figures

14

4

Back

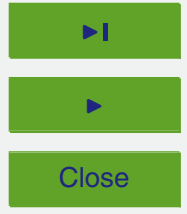

Full Screen / Esc

Printer-friendly Version

Interactive Discussion 
the form of Eq. (10), with $j=2$ (consistent with Chapman, 1999). Thus, the shorttime discharge is proportional to the reciprocal of the storage deficit (Eq. 8), and the long-term solution represents a second-order reservoir. The solution for zero aquifer thickness at the outlet therefore never behaves like a linear reservoir, even for very 5 restricted conditions.

On the other side of the spectrum, de Rooij (2013) showed that reservoirs with constant thickness may behave as linear reservoirs given a sufficiently long period during which the forcings do not change. The reservoir constant depends on the value of $a$ being zero or non-zero, and if it is, of the value of $b+R(t)$ (zero or non-zero). It should 10 be noted that the linear reservoir behaviour applies both when water exfiltrates into the stream and when the stream is feeding the aquifer. When there is a recharge flux or exchange of water with a deeper aquifer, the exponential term is superimposed upon a constant term that represents a permanent baseflow (de Rooij, 2013):

$Q(t)=K_{\text {up }}(\infty)\left[\bar{H}\left(t_{A}\right)-H_{A}+\frac{L\left(b+R+a H_{A}\right)}{a L-K_{\text {up }}(\infty)}\right] e^{\frac{\left(a L-K_{\text {up }}(\infty)\right)}{\mu L}\left(t-t_{A}\right)}-\frac{L\left(b+R+a H_{A}\right)}{\frac{a L}{K_{\text {up }}(\infty)}-1}$

15 where $t_{A}[\mathrm{~T}]$ is a reference time, conveniently chosen as the earliest time after a perturbation in the forcings for which the aquifer-scale asymptotic hydraulic conductivity $K_{\text {up }}(\infty)$ is judged to be close enough to its asymptotic value to view the aquifer as a linear reservoir from then on. The characteristic time $t_{\mathrm{c}}[\mathrm{T}]$ of the aquifer follows immediately from the exponent (de Rooij, 2013):

$20 \quad t_{\mathrm{c}}=\mu\left(\frac{K_{\mathrm{up}}(\infty)}{L}-a\right)^{-1}$.

The value of $K_{\text {up }}(\infty)$ depends on whether or not the aquifer is leaky, and on the presence of recharge/extraction (de Rooij, 2013). When the aquifer is non-leaky and recharge is zero $(a=b+R(t)=0)$, it is given by
HESSD

$11,83-108,2014$

Is the groundwater reservoir linear? A

mathematical

analysis

G. H. de Rooij

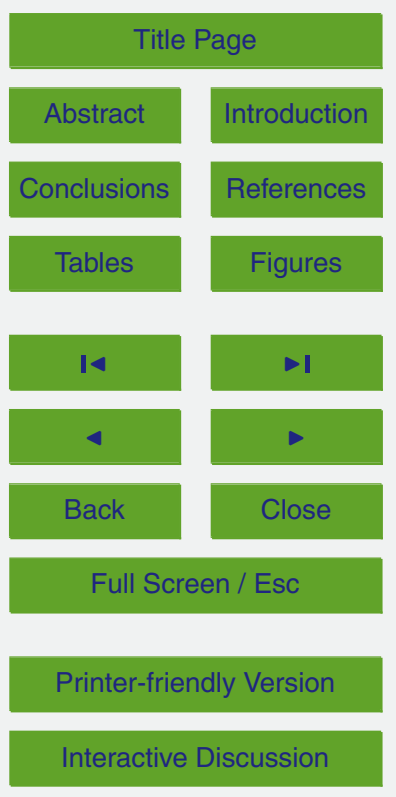

Interactive Discussion 
$K_{\text {up }}(\infty)=\frac{\pi^{2} K D}{4 L} \approx 2.46740 \frac{K D}{L}$.

HESSD

In this case, the time-independent term on the right-hand side of Eq. (12) vanishes, and the straight-forward exponentially decaying recharge familiar from recession analysis studies emerges. The characteristic time of this aquifer is:

${ }_{5} t_{\mathrm{c}}=\frac{\mu L}{K_{\mathrm{up}}(\infty)}=\frac{4 \mu L^{2}}{\pi^{2} K D} \approx 0.405285 \frac{\mu L^{2}}{K D}$.

When there is a constant, non-zero recharge of/extraction from a non-leaky aquifer $(a=0, b+R(t) \neq 0)$, the asymptotic aquifer-scale conductivity reads

$K_{\text {up }}(\infty)=\frac{3 K D}{L}$

with the corresponding characteristic time:

${ }_{10} t_{\mathrm{c}}=\frac{\mu L^{2}}{3 K D}$.

In this case, the time-independent term in Eq. (12) represents the total flux generated by the recharge/extraction divided by the length of the canal bank: $L(b+R)$.

When the aquifer is leaky $(a \neq 0)$, the expression is more elaborate:

$K_{\text {up }}(\infty)=\frac{\pi^{2} K D}{L} \frac{\sum_{n=0}^{\infty}\left\{\left[\left(n+\frac{1}{2}\right) \pi\right]^{2}-\frac{a L^{2}}{K D}\right\}^{-1}}{\sum_{n=0}^{\infty}\left[\left(n+\frac{1}{2}\right)^{4} \pi^{2}-\left(n+\frac{1}{2}\right)^{2} \frac{a L^{2}}{K D}\right]^{-1}}$.

15 By comparing Eqs. (2) and (12) it becomes clear that all terms to the right of the factor $K_{\text {up }}(\infty)$ in Eq. (12) can be used to compute the normalized average hydraulic

Is the groundwater reservoir linear? A

mathematical

analysis

G. H. de Rooij

Title Page

Abstract

Introduction

Conclusions

Tables

References

Figures

14

4

Back

Close

Full Screen / Esc

Printer-friendly Version

Interactive Discussion 
head $\bar{H}(t)-H_{A}$. This value can be relatively easily verified in the field with a limited number of monitoring wells, or, if the number of such wells is too small or their locations insufficiently representative, from a groundwater flow model calibrated on data from such wells. This is a considerable advantage over Eqs. (8) and (9) and other equations 5 that relate the flux to the storage in the aquifer, which is more difficult to determine. It is also apparent that the recharge flux (the base flow term at the end of Eq. 12) modifies the average hydraulic head, and with that the storage. If recharge is incorrectly assumed to be zero, this term is neglected, which may have led to the apparently nonlinear behaviour reported by Fenicia et al. (2006) when recharge was not accounted for. This will be explored in more detail below.

The characteristic time depends on the values of $a$ and $b+R(t)$. Thus, Fenicia et al.'s (2006) speculation that the hydrographs are affected by potential-dependent and potential-independent recharge/extraction is corroborated by the mathematical analysis presented here. For both types of recharge the aquifers will eventually behave as linear reservoirs, but with different reservoir coefficients, and superimposed on a constant flow in case of non-zero recharge/extraction.

\section{Storage-discharge relationships for aquifers of constant thickness}

The storage below the stream water level is of no interest for the generation of discharge. With that in mind, the discharge-producing storage in an aquifer can be related to its normalized average hydraulic head:

$S_{p}(t)=\theta_{s}\left(\bar{H}(t)-H_{A}\right)$

where $\theta_{s}$ is the porosity. With Eq. (2), this leads to the storage-discharge relationship for a uniform strip aquifer of constant thickness:

$Q(t)=\frac{K_{\mathrm{up}}(t)}{\theta_{s}} S_{p}(t)$
HESSD

11, 83-108, 2014

Is the groundwater reservoir linear? A

mathematical

analysis

G. H. de Rooij

Title Page

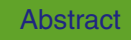

Introduction

Conclusions

Tables

References

Figures

14

$>1$

$\triangleleft$

Back

Close

Full Screen / Esc

Printer-friendly Version

Interactive Discussion 
Clearly, the relationship is linear if and only if $K_{\text {up }}(t)$ is constant, fully in line with the conditions that lead to an exponential decay of the discharge flux discussed above.

Fenicia et al. (2006) first analysed aquifers on impermeable bases without recharge. For that case, $K_{\text {up }}(\infty)$ is given by Eq. (14). The corresponding relationship is

${ }_{5} Q_{\mathrm{nr}}(t)=\frac{\pi^{2} K D}{4 L \theta_{s}} S_{p, \mathrm{nr}}(t)$.

When non-zero recharge is taken into account, Eq. (16) applies after a sufficiently long time of constant recharge, and the storage-discharge relationship becomes

$Q_{\mathrm{r}}(t)=\frac{3 K D}{L \theta_{s}} S_{p, \mathrm{r}}(t)$

The subscripts of $Q$ and $S_{p}$ indicate whether the aquifer received recharge $(r)$ or not 10 (nr).

Equation (30) of de Rooij (2013) gives en expression for $\bar{H}(t)-H_{A}$ for time periods in which the linear reservoir approximation is valid. As indicated above, the beginning of such a time period, sometime after $R$ or $H_{A}$ changed, is denoted $t_{A}$. For an aquifer on an impermeable base with constant recharge $R$, after converting $\bar{H}(t)-H_{A}$ to $S_{p}$ the

$$
\begin{aligned}
S_{p, \mathrm{r}}(t) & =\left(S_{p, \mathrm{r}}\left(t_{A}\right)-\frac{\theta_{s} L R}{K_{\mathrm{up}}(\infty)}\right) \mathrm{e}^{\frac{K_{\mathrm{up}}(\infty)}{\mu L}\left(t_{A}-t\right)}+\frac{\theta_{S} L R}{K_{\mathrm{up}}(\infty)} \\
& =\left(S_{p, \mathrm{r}}\left(t_{A}\right)-\frac{\theta_{s} L^{2} R}{3 K D}\right) \mathrm{e}^{\frac{3 K D}{\mu L^{2}}\left(t_{A}-t\right)}+\frac{\theta_{s} L^{2} R}{3 K D} .
\end{aligned}
$$

If there is no recharge, the expression simplifies further to

\section{HESSD}

$11,83-108,2014$

Is the groundwater reservoir linear? A

mathematical

analysis

G. H. de Rooij

\section{Title Page}

4
$S_{p, \mathrm{nr}}(t)=S_{p, \mathrm{nr}}\left(t_{A}\right) \mathrm{e}^{\frac{K_{\mathrm{up}}(\infty)}{\mu L}\left(t_{A}-t\right)}=S_{p, \mathrm{nr}}\left(t_{A}\right) \mathrm{e}^{\frac{\pi^{2} K D}{4 \mu L^{2}}\left(t_{A}-t\right)}$.
Full Screen / Esc

Printer-friendly Version

Interactive Discussion 
This set of relationships allows an examination of the apparent non-linearity that arose in the analysis of Fenicia et al. (2006). They initially found a storage-discharge relationship that gradually steepened with increasing storage when the effect of recharge on storage was neglected. Calibration while properly accounting for recharge resulted 5 in a linear storage-discharge relationship. Figure 4 plots the correct storage-discharge relationships for a hypothetical non-leaky aquifer (Table 1) with and without recharge. The slope of the linear relationship for the recharged aquifer is larger than that of the aquifer without recharge, which reflects the larger value of the aquifer-scale hydraulic conductivity that is used in Eq. (20a). The line for the recharged aquifer terminates at the point where the discharge flux equals the recharge flux, since the discharge flux cannot become smaller than the discharge flux when the recharge is constant and permanent. Figure 4 also presents the graph that results when the effect of recharge on the storage is ignored. This reflects step 2 of Fenicia et al.'s (2006) calibration procedure, in which the recharge was incorrectly assumed to be zero. Figure 4 confirms the curvature of Fenicia et al.'s (2006) storage-discharge relationship when recharge should not have been neglected.

The apparently non-linear storage-discharge relationship appears plausible on first sight. With increasing storage, a catchment is wetter. The saturated cross-section of the subsurface is larger and the transmissivity consequently higher. A more effective delivery of water to the stream therefore seems reasonable. The shape of the storagedischarge curve could falsely be interpreted as representative of the hydrogeological make-up of the catchment's aquifers. The findings reported by Felicia et al. (2006) and in this paper lead to the recommendation to consider the magnitude of recharge carefully before deciding how to interpret a curved storage-discharge relationship.

\section{HESSD}

$11,83-108,2014$

Is the groundwater reservoir linear? A

mathematical analysis

G. H. de Rooij

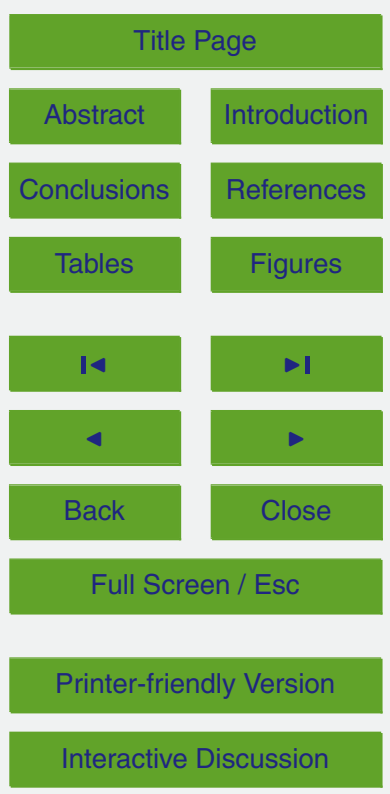




\section{Effects of changes in surface water level and recharge on deviations from linear-reservoir behaviour}

HESSD

In the above it has been established that aquifers of constant thickness can behave like linear reservoirs if the recharge and the surface water level are constant for a sufficiently 5 long time, without further defining the length of this time period. It is worth noticing that de Rooij's (2012) full solution of Eq. (5) yields an equation for $Q$ in the form of an infinite series (de Rooij, 2012, Eq. 38):

$$
Q(t)=\frac{2 K D}{L} \sum_{n=0}^{\infty}\left[\begin{array}{l}
\left(H_{0}-H_{A}\right) \mathrm{e}^{\left\{a-\frac{K D}{L^{2}}\left[\left(n+\frac{1}{2}\right) \pi\right]^{2}\right\} \frac{t}{\mu}} \\
+\frac{a H_{A}+b+R_{1}}{\frac{K D}{L^{2}}\left[\left(n+\frac{1}{2}\right) \pi\right]^{2}-a}\left(1-\mathrm{e}^{\left\{a-\frac{K D}{L^{2}}\left[\left(n+\frac{1}{2}\right) \pi\right]^{2}\right\} \frac{t}{\mu}}\right) \\
+u\left(t-t_{1}\right) \frac{\left(R_{2}-R_{1}\right)}{\frac{K D}{L^{2}}\left[\left(n+\frac{1}{2}\right) \pi\right]^{2}-a}\left(1-\mathrm{e}^{\left\{a-\frac{K D}{L^{2}}\left[\left(n+\frac{1}{2}\right) \pi\right]^{2}\right\}\left(\frac{t-t_{1}}{\mu}\right)}\right)
\end{array}\right] .
$$

10 Each term of the series has three flux components that are added. Two of those are of particular interest:

$\frac{2 K D}{L}\left(H_{0}-H_{A}\right) \mathrm{e}^{\left\{a-\frac{K D}{L^{2}}\left[\left(n+\frac{1}{2}\right) \pi\right]^{2}\right\} \frac{t}{\mu}}$

and

$u\left(t-t_{1}\right) \frac{2\left(R_{2}-R_{1}\right)}{\frac{1}{L}\left[\left(n+\frac{1}{2}\right) \pi\right]^{2}-\frac{a L}{K D}}\left(1-\mathrm{e}^{\left\{a-\frac{K D}{L^{2}}\left[\left(n+\frac{1}{2}\right) \pi\right]^{2}\right\} \frac{t-t_{1}}{\mu}}\right)$

15 where $H_{0}[\mathrm{~L}]$ is the uniform initial hydraulic potential, $R_{1}$ and $R_{2}\left[\mathrm{LT}^{-1}\right.$ ] are the recharge rates before and after time $t_{1}[\mathrm{~T}]$, respectively, and $u(t)$ is the Heaviside step function. Equation (23) describes how the effect on $Q$ of a change in the surface water level damps out for the $n$th term of the series. Obviously, the higher-order terms damp out

Is the groundwater reservoir linear? A

mathematical

analysis

G. H. de Rooij

Title Page 
much faster than the lower-order terms. Equation (24) describes how long it takes for a change in recharge/extraction to fully affect the flux into (or from) the stream. The terms with large values of $n$ deliver their full contribution to the flux much earlier than the terms with small $n$. The fractional term in the middle constitutes a weighting factor in 5 the series that decreases with increasing $n$. Thus, the rapidly contributing high- $n$ terms are given less weight in the full solution. Overall, the effects of a change in recharge are therefore expected to linger longer than the effect of a change in the stream level, which will affect the time needed to settle down into linear reservoir behaviour superimposed on a constant base flow. This is corroborated by trial calculations that show that 10 for $a=0$, the linear reservoir approximation requires less than 2 characteristic times to approximate the flux according to the full solution within $1 \%$ after a change in the surface water potential during zero recharge. After a step change in recharge/extraction (starting from hydrostatic equilibrium and zero recharge), approximately 8 characteristic times are needed for the linear reservoir approximation to come within $1 \%$ of the 15 full solution. For a non-leaky, $3 \mathrm{~m}$ thick, sandy aquifer $\left(K=1 \mathrm{md}^{-1}, \mu=0.3\right)$ with drains $30 \mathrm{~m}$ apart, the characteristic time is $7.5 \mathrm{~d}$ for periods with recharge/extraction and $9.1 \mathrm{~d}$ for periods without. If an aquifer of the same material is $50 \mathrm{~m}$ thick and is intersected by rivers $10 \mathrm{~km}$ apart, the characteristic times are 137 and $166 \mathrm{yr}$, respectively.

If the $3 \mathrm{~m}$ thick aquifer described above overlays an aquitard with a resistance of 100 20 days that separates it from a deeper aquifer in which the hydraulic potential is $0.5 \mathrm{~m}$ larger than the surface water level (see Table 2 for full details), the upscaled hydraulic conductivity becomes $0.629 \mathrm{md}^{-1}$. Its characteristic time is $5.8 \mathrm{~d}$, irrespective of the occurrence of recharge/extraction. The flux according to the linear reservoir approximation approximates the true value within $1 \%$ after about 8 characteristic times. If the resistance of the aquitard is increased tenfold, the characteristic time becomes $7.3 \mathrm{~d}$, and over nine characteristic times are needed to approximate the true flux within $1 \%$. That flux, however, is much smaller owing to the limitation of the exchange between the two aquifers on either side of the aquitard. The increase of the aquitard's resistance causes the characteristic time to trend toward the value for the non-leaky aquifer

\section{HESSD}

$11,83-108,2014$

Is the groundwater reservoir linear? A

mathematical analysis

G. H. de Rooij

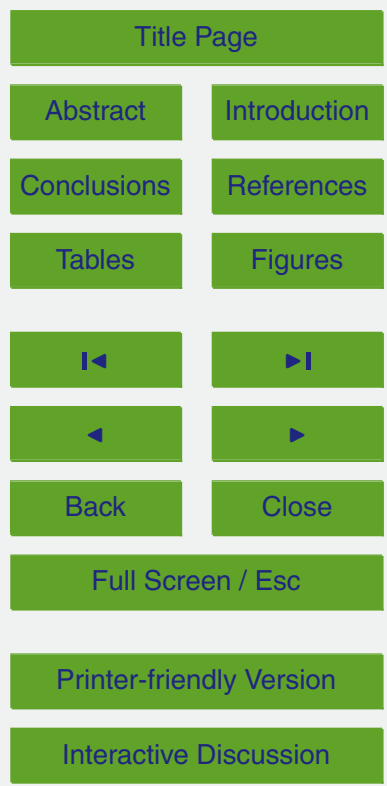


with recharge. When the resistance is about $3 \times 10^{4} \mathrm{~d}$, the deviation of the upscaled conductivity from its value for the non-leaky aquifer with recharge is less than $0.1 \%$.

From the above it appears that large systems will never behave like linear reservoirs. But systems with dense drainage networks can realistically be expected to be5 have linearly part of the time. The most dynamic periods immediately after changes in the forcings will be non-linear though. Together with other fast-response mechanisms (overland flow, preferential flow, etc.) this non-linear groundwater signal creates the early response of a catchment. Particularly if solute transport is of interest, it is important to realize that the fast-response reservoir(s) in a conceptual catchment model not only represent(s) signals generated by overland flow and preferential flow, but also have a groundwater component. Thus, for some time after a change in recharge or surface water level, the model lacks process realism, and therefore fails to meet the criterium of being "right for the right reasons", compromising its predictive capability (Tetzlaff et al., 2013).

As a general rule, aquifers with characteristic times in the order of $10^{2} \mathrm{~d}$ are unlikely to ever attain linear-reservoir behaviour in climates with frequent precipitation sufficient to produce recharge at least once a year (which would normally be expected if surface water is present in the landscape). If streams or rivers are spaced several kilometres apart, the characteristic time can easily exceed years or even centuries, as demonstrated above. But even small systems can take a few months to revert to linear behaviour after a sudden change in the recharge/extraction rate. When rainfall is fairly uniformly distributed over the year and the unsaturated zone damps the recharge signal, linear-reservoir behaviour is increasingly likely. A full exploration of this would require a convolution of de Rooij's (2012) full solution to the flow problem for successive 25 stepwise changes in recharge to reflect the day-to-day variations. Such an analysis is beyond the scope of this paper.

\section{HESSD}

11, 83-108, 2014

Is the groundwater reservoir linear? A

mathematical analysis

G. H. de Rooij

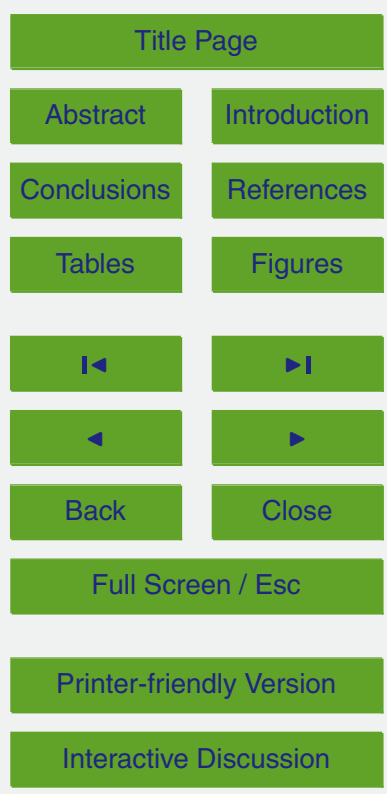




\section{Summary and conclusions}

The linear behaviour of horizontal aquifers with parallel flow lines was examined through mathematical analysis. Any aquifer with a strongly curved phreatic level caused by a stream water level that is close to the underlying impermeable bedrock is unlikely 5 to exhibit linear reservoir behaviour. Phreatic aquifers that are deep compared to the variations in their hydraulic potential and are drained by a relatively dense network of streams can behave like linear reservoirs if the stream level and the recharge/extraction do not vary too much. Particularly changes in the recharge/extraction can cause the aquifer to deviate from linearity for periods in the order of months for small systems, 10 and years or centuries for large systems. Therefore, the answer to the question in Fenicia et al.'s (2006) title "Is the groundwater reservoir linear?" is: only if the circumstances are favourable. Favourable circumstances require slopes to be small or zero, the aquifer thickness to be constant, the surface water level to remain constant for about 2 characteristic times and the recharge to remain constant for 8 or more characteristic 15 times.

The characteristic time of the groundwater reservoir differs between leaky and nonleaky aquifers, and for non-leaky aquifers depends on the presence or absence of recharge/extraction. Thus, care should be taken in extrapolating the behaviour of a groundwater reservoir observed in a recession phase (recharge-free) to other periods: an appropriate correction factor that can be obtained from the different expressions of $K_{\text {up }}(\infty)$ should be used to account for the different values of the aquifer-scale hydraulic conductivity in the expression for the characteristic time.

Discharges in excess of that generated by the linear reservoir may be produced by the groundwater reservoirs for some time after a perturbation, when the linear 25 reservoir approximation is not yet valid. In conceptual models such as that of Fenicia et al. (2006) such fluxes will be assigned to another reservoir with a faster response. This may be acceptable when the discharge quantity is modelled within the calibration range, but as soon as the model is used for extrapolation or the water quality becomes
HESSD

$11,83-108,2014$

Is the groundwater reservoir linear? A mathematical analysis

G. H. de Rooij

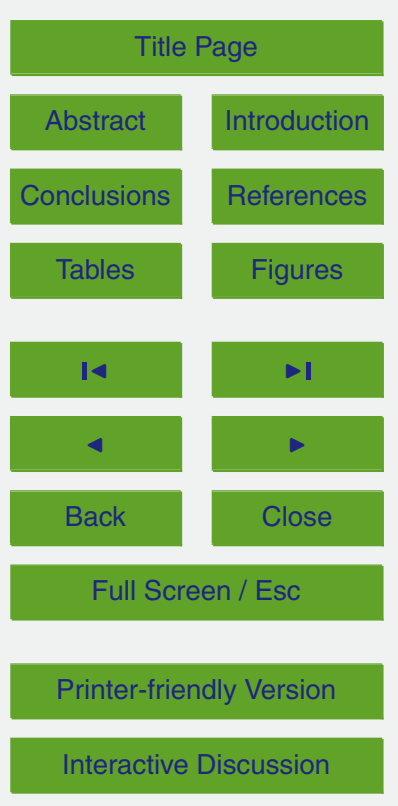


of interest, assigning fluxes to the wrong reservoir may lead to erroneous predictions of water fluxes and solute loads.

The service charges for this open access publication

5 have been covered by a Research Centre of the

Helmholtz Association.

\section{References}

Birtles, A. B.: Identification and separation of major base flow components from a stream hydrograph, Water Resour. Res., 14, 791-803, 1978.

10 Boussinesq, J.: Recherches throretique sur l'rcoulement des nappes d'eau infiltres duns le sol et sur le drbit des sources, J. Math. Pure. Appl., 10, 5-78, 1904.

Brutsaert, W.: Hydrology. An introduction, Cambridge Univ. Press, Cambridge, UK, 605 pp., 2005.

Brutsaert, W. and Nieber, J. L.: Regionalized drought flow hydrographs from a mature glaciated plateau, Water Resour. Res., 13, 637-643, 1977.

Chapman, T.: A comparison of algorithms for stream flow recession and baseflow separation, Hydrol. Process., 13, 701-714, 1999.

de Rooij, G. H.: Transient flow between aquifers and surface water: analytically derived fieldscale hydraulic heads and fluxes, Hydrol. Earth Syst. Sci., 16, 649-669, doi:10.5194/hess16-649-2012, 2012.

de Rooij, G. H.: Aquifer-scale flow equations as generalized linear reservoir models for strip and circular aquifers: links between the Darcian and the aquifer scale, Water Resour. Res., doi:10.1002/2013WR014873, in press, 2013.

Fenicia, F., Savenije, H. H. G., Matgen, P., and Pfister, L.: Is the groundwater reservoir linear? Learning from data in hydrological modelling, Hydrol. Earth Syst. Sci., 10, 139-150, doi:10.5194/hess-10-139-2006, 2006.

Hilberts, A. G. J., van Loon, E. E., Troch, P. A., and Paniconi, C.: The hillslopestorage Boussinesq model for non-constant bedrock slope, J. Hydrol., 291, 160-173, doi:10.1016/j.jhydrol.2003.12.043, 2004.

\section{HESSD}

$11,83-108,2014$

Is the groundwater reservoir linear? A

mathematical

analysis

G. H. de Rooij

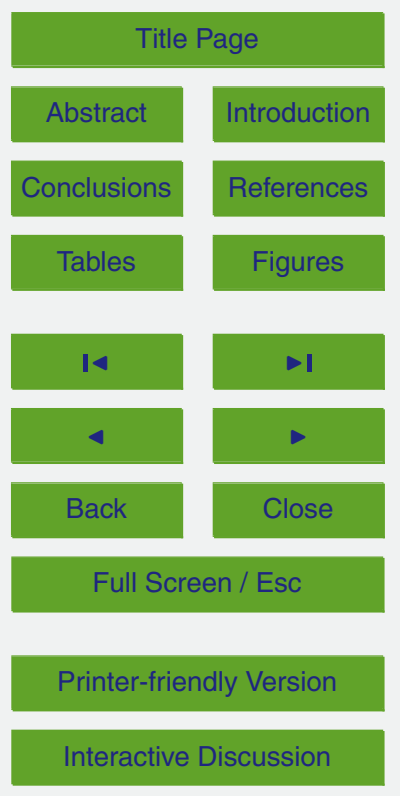


Hornberger, G. M., Wiberg, P. L., Raffensperger, J. P., and Eshleman, K. N.: Elements of Physical Hydrology, Johns Hopkins Univ. Press, Baltimore, USA, 302 pp., 1998.

Moore, R. D.: Storage-outflow modelling of streamflow recessions, with application to a shallowsoil forested catchment, J. Hydrol., 198, 260-270, 1997.

5 Tallaksen, L. M.: A review of baseflow recession analysis, J. Hydrol., 165, 349-370, 1995.

Tetzlaff, D., Al-Rawas, G., Blöschl, G., Carey, S. K., Ying, F., Hrachowitz, M., Kirnbauer, R., Jewitt, G., Laudon, H., McGuire, K. J., Sayama, T., Soulsby, C., Zehe, E., and Wagener, T.: Process realism: flow paths and storage, calibration, in: Runoff Prediction in Ungauged Basins, Synthesis Across Processes, Places and Scales, edited by: Blöschl, G., Sivapalan, M., Wagener, T., Viglione, A., and Savenije, H., Cambridge University Press, Cambridge, UK, 53-69, 2013.

Troch, P. A., Paniconi, C., and van Loon, E. E.: Hillslope-storage Boussinesq model for subsurface flow and variable source areas along complex hillslopes: 1. Formulation and characteristic response, Water Resour. Res., 39, 1316, doi:10.1029/2002WR001728, 2003.

Vogel, R. M. and Kroll, C. N., Regional geohydrologic-geomorphic relationships for the estimation of low-flow statistics, Water Resour. Res., 28, 2451-2458, 1992.

Werner, P. W. and Sundquist, K. J.: On the groundwater recession curve for large water-sheds, IAHS-AISH P., 33, 202-212, 1951.

Wittenberg, $\mathrm{H}$.: Effects of season and man-made changes on baseflow and flow recession: case studies, Hydrol. Process., 17, 2113-2123, doi:10.1002/hyp.1324, 2003.

Wittenberg, $\mathrm{H}$. and Sivapalan, M.: Watershed groundwater balance estimation using streamflow recession analysis and baseflow separation, J. Hydrol., 219, 20-33, 1999.

Zecharias, Y. B. and Brutsaert, W.: Recession characteristics of groundwater outflow and base flow from mountainous watersheds, Water Resour. Res., 24, 1651-1658, 1988.

Is the groundwater reservoir linear? A

mathematical analysis

G. H. de Rooij

Title Page

Abstract Introduction

Conclusions

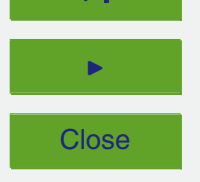


Table 1. Parameter values for the non-leaky aquifer.

\begin{tabular}{ll}
\hline$K\left(\mathrm{~m} \mathrm{~d}^{-1}\right)$ & 1.0 \\
$D(\mathrm{~m})$ & 2.0 \\
$L(\mathrm{~m})$ & 50.0 \\
$\mu$ & 0.2 \\
$S_{p}\left(t_{A}\right)(\mathrm{m})$ & 0.525 \\
$R\left(\mathrm{~m} \mathrm{~d}^{-1}\right)$ & 0.002 \\
$\theta_{s}$ & 0.35 \\
$a\left(\mathrm{~d}^{-1}\right)$ & 0 \\
$b\left(\mathrm{md}^{-1}\right)$ & 0 \\
\hline
\end{tabular}

HESSD

11, 83-108, 2014

Is the groundwater reservoir linear? A mathematical analysis

G. H. de Rooij

Title Page

Abstract Introduction

Conclusions

References

Tables

Figures

14

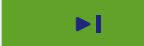

4

Back

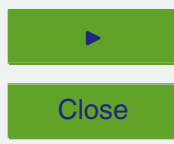

Full Screen / Esc

Printer-friendly Version

Interactive Discussion 
Table 2. Parameter values for the leaky aquifer.

\begin{tabular}{ll}
\hline$K\left(\mathrm{md}^{-1}\right)$ & 1.0 \\
$D(\mathrm{~m})$ & 3.0 \\
$L(\mathrm{~m})$ & 15.0 \\
$\mu$ & 0.3 \\
$H_{0}(\mathrm{~m})$ & 1.0 \\
$H_{A}(\mathrm{~m})$ & 1.5 \\
$R_{1}\left(\mathrm{md}^{-1}\right)$ & 0.0 \\
$R_{2}\left(\mathrm{md}^{-1}\right)$ & 0.0 \\
$t_{1}^{*}(\mathrm{~d})$ & $\infty$ \\
$a\left(\mathrm{~d}^{-1}\right)$ & -0.01 \\
$b\left(\mathrm{md}^{-1}\right)$ & 0.02 \\
\hline
\end{tabular}

\section{HESSD}

11, 83-108, 2014

Is the groundwater reservoir linear? A mathematical analysis

G. H. de Rooij

\section{Title Page}

\section{Abstract} Introduction

Conclusions

References

Tables

Figures

14

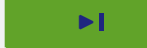

4

Back

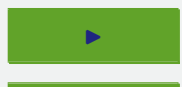

Close

Full Screen / Esc

Printer-friendly Version

Interactive Discussion 


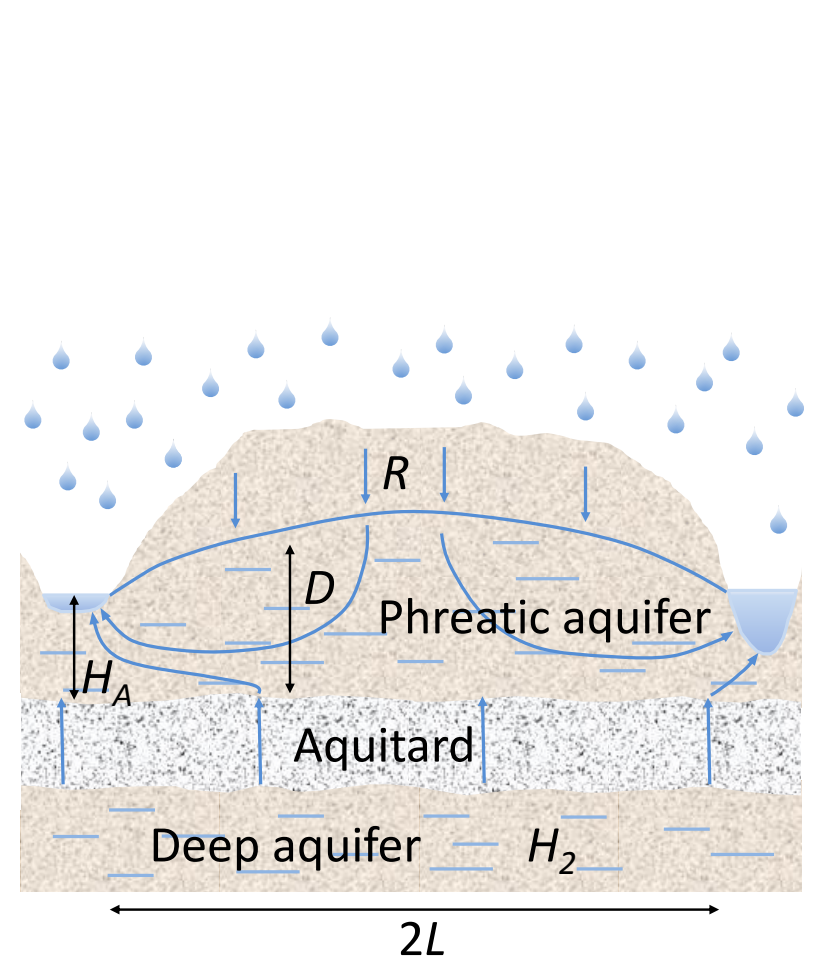

\section{HESSD}

$11,83-108,2014$

Is the groundwater reservoir linear? A mathematical analysis

G. H. de Rooij

\section{Title Page}

Fig. 1. Cross-section of a strip aquifer between two parallel canals or streams. The aquifer receives recharge from the unsaturated zone above and from a deeper aquifer at constant hydraulic head below. The symbols are defined in the text.

\section{4}

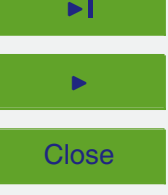

Full Screen / Esc

Printer-friendly Version

Interactive Discussion 


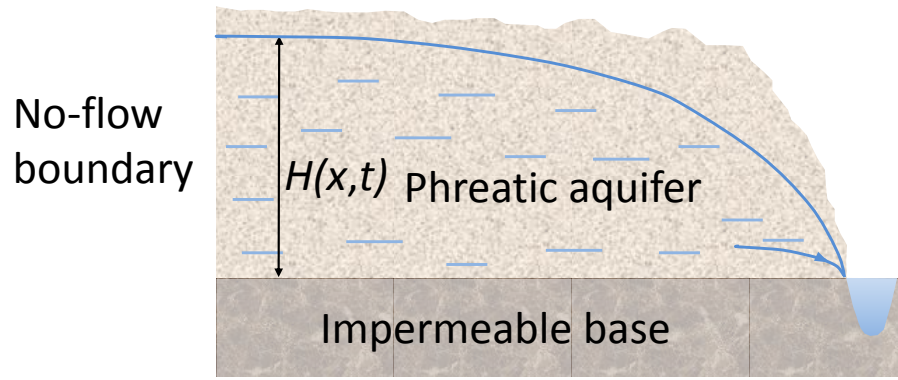

HESSD

$11,83-108,2014$

Is the groundwater reservoir linear? A mathematical analysis

G. H. de Rooij

Title Page

Abstract Introduction

Conclusions References

Fig. 2. A definition sketch of the Dupuit-Boussinesq aquifer. The surface water is at the same level as the aquifer bottom. The aquifer receives recharge neither from above nor below. The symbols are defined in the text. 


\section{HESSD}

$11,83-108,2014$

Is the groundwater reservoir linear? A mathematical analysis

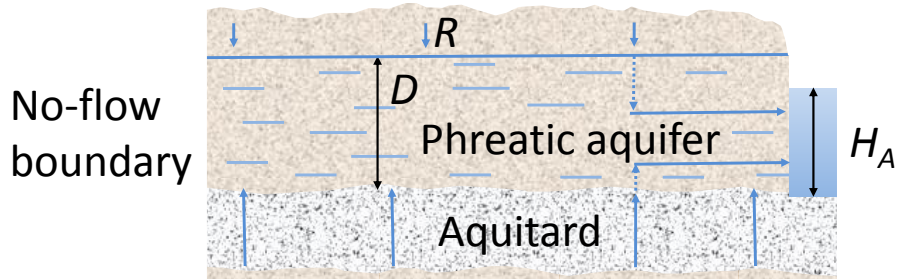

$$
\text { Deep aquifer } \quad \mathrm{H}_{2}
$$
$L$

Fig. 3. A definition sketch of the aquifer for which the linearized Boussinesq-equation is valid because its thickness $D$ can be assumed constant and uniform. In the most general case, the aquifer receives recharge from above and below (compare Fig. 1).

G. H. de Rooij

\section{Title Page}

Abstract

Conclusions

Tables

14

4

Back

Full Screen / Esc

Printer-friendly Version

Interactive Discussion 


\section{HESSD}

$11,83-108,2014$

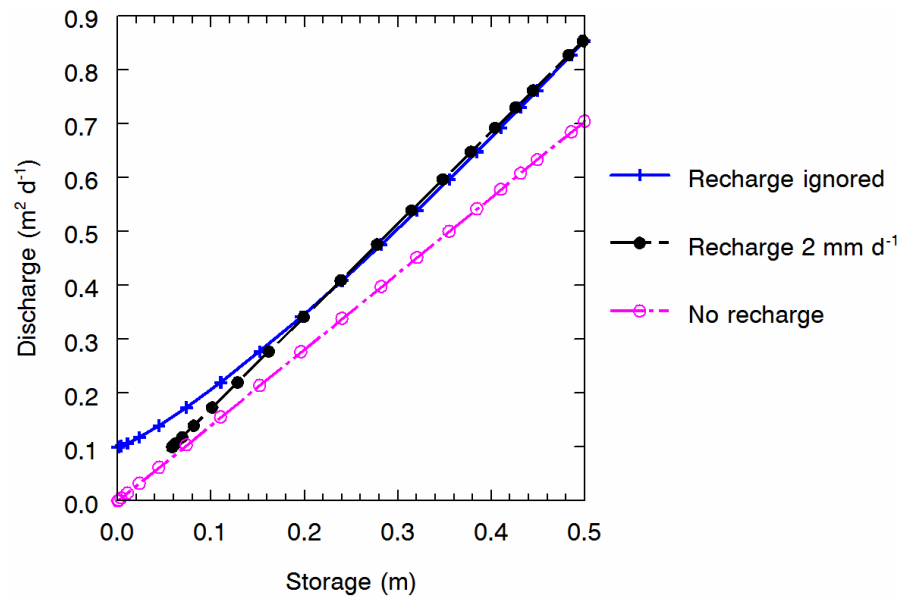

Is the groundwater reservoir linear? A mathematical analysis

G. H. de Rooij

Title Page

Abstract Introduction

Conclusions References

Tables Figures

Fig. 4. Storage-discharge relationships for the hypothetical non-leaky aquifer described in Table 1 and Fig. 3, for the case with and without recharge. The apparent storage-discharge relationship that emerges in case the aquifer receives recharge but the effect on storage is incorrectly assumed to be zero is also given.

\section{4}

4

\section{Back}

Full Screen / Esc

Printer-friendly Version

Interactive Discussion 